\title{
A REFORMA PENITENCIÁRIA E A MODERNIDADE NO BRASIL: UMA ABORDAGEM POSSÍVEL
}

Mozart Linhares da Silva*

SÍNTESE - $O$ autor examina o Instituto de Reforma Peninteciária desde suas origens no Modernismo e relaciona-a com o Direito e com a Antropologia Criminal.
ABSTRACT - This article presents a view on the brazilian Penitentiary Reform in the light of modernity. The modernity brazilian's sight is apreciated showing how it obstruct a less negative vision about the Brazil's History.

\section{Introdução}

Qual é a relação entre a reforma penitenciária da metade do século XIX, ocorrida no Brasil, na Europa e na América, com a modernidade? Responder a esta questão é desenvolver um conceito de reforma penitenciária que traga em discussão o próprio conceito de modernidade. Este ensaio se propõe a responder esta questão. Para tanto dividirei o desenvolvimento à resposta em dois itens, são eles: 1) a ideologia da modernização; 2) modernidade e reforma penitenciária: uma abordagem possível. No primeiro item pretendo discutir uma certa visão de modernidade que se tem no Brasil e como ela impede uma abordagem menos obstinada e negativa da história brasileira e, conseqüentemente, sobre o conceito de reforma penitenciária. No segundo, desenvolvo uma abordagem conceitual da reforma penitenciária relacionando-a com o conceito de modernidade.

\section{1 - A ideologia da modernização}

A modernidade brasileira sempre foi um problema para os intelectuais e políticos brasileiros. Adotamos um caminho negativo para entender a modernidade e este caminho acabou determinando um modo de pensar a sociedade brasileira de forma maniqueísta e simplória. Não é o caso, neste ensaio, de tratarmos dos problemas políticos relacionados com esta visão de modernidade e sim de buscarmos entender em que bases lógicas se assenta esta maneira de entender a modernidade.

* Mestrando do Curso de Pós-Graduação em História da PUCRS.

\begin{tabular}{|l|l|l|l|l|l|}
\hline VERITAS & Porto Alegre & v. 40 & $\mathrm{n}^{2} 158$ & Junho 1995 & p. 255-261 \\
\hline
\end{tabular}


A modernidade é pensada como se ela fosse inacabada, enquanto projeto futuro e sem efeitos positivos no presente. O grande problema é sempre a retomada do desenvolvimento que nos levaria à modernidade. Falta para o Brasil, assim como para todos os países do dito terceiro mundo, mas para o Brasil em particular, encontrar um caminho histórico possivel para chegar à modernidade. Esta forma de pensar o Brasil e a modernidade tem por base o que Léa Perez chama de lógica da falta. Segundo Perez, "esta concepção se articula em torno de uma 'lógica da falta', operando a partir de oposições binárias, sobretudo com as oposições tradicional-moderno e centro-periferia". ${ }^{1}$

É neste sentido que no Brasil as idéias são sempre importadas, e importadas porque modernas, e aplicadas internamente. Sua aplicação à realidade brasileira, via de regra, é negativa pois são idéias modernas aplicadas a um país ainda tradicional. A modernidade seria então importada e ilusória.

A frustração com relação à modernidade possui, segundo esta lógica, causas históricas precisas: a colonização portuguesa. ${ }^{2}$ Esta impediu que o Brasil tomasse o rumo do desenvolvimento junto com as outras nações do mundo ocidental. O colonialismo teria deixado o Brasil numa situação tradicional que se mantém até os dias atuais.

É fácil entender que esta visão fez com que o Brasil olhasse sempre para cima, sempre para o que é moderno, para o que dá o norte. Este norte tem uma implicação ideológica muito forte, ou seja, se materializa na forma da teoria do desenvolvimento e da modernização. Desenvolvida a partir da Segunda Guerra Mundial, já possuía uma certa receptividade interna no Brasil. Para isto basta olhar os discursos políticos em prol do desenvolvimento nos séculos XIX, os projetos institucionais e econômicos.

A ideologia da modernização, no entanto, possui dois viéses. No Terceiro Mundo seu reflexo criou uma lógica da falta e da dependência. No Primeiro Mundo serviu para justificar os caminhos políticos e econômicos adotados. Neste sentido, a ideologia da modernização impõe para a modernidade etapas de desenvolvimento internos que diferenciam as sociedades. Temos a partir daí dois pontos de vista que se confrontam mas possuem a mesma matriz de pensamento lógico. Estas duas formas de pensar a sociedade moderna podem ser resumidas na escola funcionalista e na escola crítica. Considerando duas teorias explicativas da sociedade temos: a tradicional e a crítica. A primeira é absorvida pelo sistema, a segunda, por desconfiar das sinteses e das reconciliações, escapa deste destino e não é desejada pelo sistema. A primeira tornou-se inerte perante o sistema e a segunda se autoflagelou, perdendo vigor e representatividade plausivel de ser incorporada. ${ }^{3} \mathrm{~A}$ primeira escola é representada por Parsons e a segunda, pelo marxismo.

1 PEREZ, Léa Freitas. "Por uma poética do sincronismo tropical". In Estudos Ibero-Americanos, PUCRS, V. XVIII, no 2, p. 43-52, dezembro, 1992. p. 44.

2 Sobre a negatividade da colonização portuguesa no Brasil ver: HOLANDA, Sérgio Buarque de. Raizes do Brasil. $16^{2}$ ed. Rio de Janeiro: José Olympio Editora, 1983 e PRADO JÚNIOR, Caio. Formação do Brasil contemporâneo. 21ª̂ ed, São Paulo: Brasiliense, 1989.

3 LYOTARD, Jean-François. O pós-moderno. $3^{a}$ ed. trạução Ricardo Corrêa Barbosa, Rio de Janeiro: José Olympio. 1988. cap 4. 
O discurso de ambas escolas possui, como já frisei, a mesma base lógica. Possuem ambas um projeto de realização social, porém pregam meios diferentes para 0 alcance deste objetivo.

A modernidade enquanto projeto racional, única forma possível de realização social, parece ter se tornado uma palavra mestra no sentido que Morin a atribui. ${ }^{4} \mathrm{O}$ termo modernidade, no Brasil, está impregnado de frustração, por um lado, e esperança, por outro. É exatamente estes contrários que atribuem à palavra modernidade um sentido que lhe dá vida própria. Modernidade enquanto frustração entendida como falta crônica, desejo quase impossivel. Modernidade enquanto esperança, no sentido de ser a saída possível de uma fase tradicional para uma moderna. 0 meio para este fim: a modernização. A força que o vocábulo modernidade - e seus sentidos paradoxais - adquiriu no Brasil fez com que se criasse uma relação endógena entre modernidade e modernização e técnica. O conceito de modernidade é absorvido pelo sentido técnico que o conceito de modernização possui. Isto provoca uma confusão conceitual que não permite um olhar sobre a modernidade sem ter como referenciais a medida do desenvolvimento técnico. Entre toda esta parafernalha de conceitos, que servem de armas poderosas na luta política, há uma luta também pelo vocabulário. Morin se refere a uma batalha das palavias. Poderia acrescentar ainda, pelas palavras. ${ }^{5}$

De acordo com o uso que se faz das palavras pode-se desgastá-las, inflacionálas ou supervalorizá-las segundo o sentido e o grau que lhes colocamos. Neste sentido, há uma batalha ideológica de diversas concepções em torno de significados que vão sendo atribuídos às palavras que são ou se tornarão mestras, podendo também se tornarem vazias. A palavra modernidade parece ter se tornado mestra. Ocorre, e isto sim é interessante, um uso comum tanto na escola tradicional como na escola crítica. Isto porque na palavra modernidade está subentendido o sentido de projeto, futuro, devir.

No Brasil esta idéia, ou melhor dizendo, esta concepção de modernidade, teve custos elevados, política e cientificamente, sem entrar aqui no mérito da separação destes conceitos. O Brasil é visto como dependente e pouco original em seus feitos. Neste modo de pensar a sociedade brasileira, a modernidade representa o objetivo primeiro que deve ser alcançado via modernização. O Brasil sendo uma sociedade tradicional deve retomar o trem da história, modernizar-se para não precisar copiar do Exterior as idéias organizadoras da sociedade brasileira. Segundo Léa Perez, "existe, portanto, uma clara visão da existência de um centro, que é a vanguarda onde tudo é criado - de forma original - e que, nessa medida, tudo comanda, e de uma periferia, que não passa de uma retaguarda, onde tudo é cópia e, sendo cópia, é sem originalidade. As sociedades do Terceiro Mundo seriam subde-

4 MORIN Edgar. Para sair do Século XX. Tradução de Vera Azambuja Harvey. Rio de Janeiro: Nova Fronteira, 1986. p. 58.

5 "As palavras mestras [...] são estrategicamente palavras-chave e a batalha ideológico-politica, que certamente não se reduz a uma batalha de palavras, é também uma batalha que se trava com as palavras. Lutamos por um lado para impor nosso vocabulário, inclusive ao adversário: e por outro, para nos apropriarmos das palavras que, como revolução, socialismo e nação, permitem o controle de um vasto território ideológico". MORIN. Op. cit., p. 68. 
senvolvidas, pois elas não teriam conhecido, por causa do 'colonialismo', um desenvolvimento igual ao das nações européias". ${ }^{6}$

Pensar a reforma penitenciária enquanto movimento moderno contemporâneo a nações do Primeiro Mundo incorreriam então num erro grave, pois estaríamos desprezando um atraso histórico que incompatibiliza tal equiparação analítica. Meu propósito neste ensaio é mostrar exatamente o contrário desta concepção. 0 estudo da reforma penitenciária é um pretexto, serve como laboratório, como recurso para experenciar a hipótese de que se pode pensar a modernidade no Brasil sem cair nos percalços das duas escolas acima mencionadas e, mais especificamente, da lógica da falta.

A oposição tradicional x moderno é o grande problema que a lógica da falta denuncia. A modernidade como fase à frente do tradicional. Uma visão linear e evolucionista que se reveste em discurso, que pretende ser o reflexo da realidade brasileira. O primeiro passo que deve ser dado para escapar das amarras de uma visão como esta é estar disposto a um novo olhar, uma nova maneira de ver, mais aberta e menos negativa. É nesse sentido que tento, a seguir, desenvolver uma abordagem sobre a reforma penitenciária brasileira e sua relação com a modernidade.

\section{2 - A modernidade e a reforma penitenciária: uma abordagem possível}

A modernidade não implica uma ruptura com a tradição, um abandono do que é dito velho e passadista. Segundo Braudrillard, "[...] a modernidade 'não é jamais mudança radical ou revolução', ao contrário, ela sempre entra em implicação com a tradição num jogo cultural sutil, num processo de amálgama e de adaptação"?

Não se faz a ruptura e sim a composição do processo histórico. Composição no sentido de compor, de compartilhar e amarrar. Tradicional e moderno podem ser vistos de forma menos dicotômica, menos determinista no sentido de evolução por estágios, no caso, tradicional $\rightarrow$ moderno. É neste sentido que posso "contemporanizar" o Brasil e a Europa (Mundo Ocidental). Fora de uma lógica puramente temporal e linear, posso observar a contemporaneidade do espirito que envolve a cultura moderna. Procurar não um estágio moderno e sim um espirito moderno. Este significa a força motivadora da ação material. Nơ caso em pauta, o projeto que leva a realização material da reforma penitenciária. Não quero dizer com isto que ignoro o resultado material, pelo contrário, este ajuda a avaliar as características do projeto, mas não é visto como a única forma de expressão de uma determinada sociedade, nação ou indivíduo. Neste sentido, posso avaliar a construção de um presídio brasileiro, com capacidade para 250 presos, enquanto realização de um projeto racional moderno, sem, no entanto, atribuir a sua aparência material, comparada a um presídio francês, com capacidade para 2.500 presos, o estágio de desenvolvimento moderno que este possui. Ambos possuem o mesmo espírito ra-

6 PEREZ Op. cit., p. 45.

7 BRAUDRILIARD. Apud PEREZ. Op cit., p. 49. 
cional moderno, diferem materialmente, em grandiosidade arquitetônica mas não em projeto.

O que interessa mostrar na análise da reforma penitenciária brasileira é o sentido da ação que o projeto adota. Verificar a intencionalidade e, assim, explicitar o espírito que move o projeto. A noção de projeto, enquanto moderno, é baseada no conceito de ação social de Weber. Entre as quatro formas de ação social, conceituadas por este autor, uma revela com maior intensidade o espírito moderno: a ação lógico-racional com relação a um objetivo. ${ }^{8}$ Este tipo de ação social revela 0 melhor sentido de projeto, sentido de planejamento racional, cálculo, direção e utilidade.

A partir destes pressupostos, posso conceituar a reforma penitenciária sem perder a relação com o conceito de modernidade e, assim, operacionalizar este conceito historicamente no Brasil, no século XIX.

A reforma penitenciária é um movimento ocorrido entre os séculos XVIII e $\mathrm{XIX}$, que pretendia reformar os sistemas penitenciários tradicionais anteriores à Revolução Francesa. O referencial Revolução Francesa é usado como marco temporal significativo, pois foi o movimento francês que principalmente impulsionou a reforma penitenciária. A reforma penitenciária, no entanto, respeita uma lógica que precisa ser analisada enquanto sentido e diretriz. Refiro-me à principal característica da reforma penitenciária e que diz respeito explicitamente à modernidade: a racionalização metódica e intencional que pretende o alcance de um objetivo específico: a regeneração ou correção de indivíduos delinqüentes através de formas disciplinares adequadas ao capitalismo moderno.

A intermediação do Estado nas relações entre o indivíduo e a sociedade, especificamente nas formas de organização disciplinares ordenadoras da vida social, são instrumentalizadas através de duas "ciências" importantes dentro da modernidade: o Direito e a Antropologia Criminal. O primeiro antecede à segunda, obviamente, mas a segunda vai dar sustentação científica a um tipo de ação do primeiro, no que diz respeito à criminalidade.

O século XIX é o século dos direitos. O Direito passa, neste século, a ser o instrumento de organização social racional por excelência do Estado. Várias questões determinantes sobre as relações entre o indivíduo e a sociedade passam a ser objeto da ciência jurídica. ${ }^{9}$ É de extrema importância para este trabalho avaliar a posição do Direito e, mais especificamente, do Direito Penal, na formação do Estado Moderno, sua relação com o conceito de indivíduo e de sociedade e seu poder normatizador das relações sociais. Não é o caso de fazer este exame agora; no entanto, algumas observações precisam ser feitas.

O século XIX é o século onde o Estado se transforma em Estado de Direito que, segundo Bobbio, é "o estado no qual todo o poder é exercido no âmbito de regras jurídicas que delimitam sua competência e orientam (ainda que freqüente-

8 ARON, Raymond. As etapas do pensamento sociológico. São Paulo/Brasilia: Martins Fontes/UNB. 1982 p. 464.

$9 \quad$ Entre as várias questões que o Direito vai abarcar no século XIX, uma é de grande importância para entender as relações entre o indivíduo e a sociedade: legitimar os preceitos da declaração dos direitos do homem e do cidadão de 1789. Para esta questão, ver BOBBIO, Norberto. $A$ era dos direitos. Rio de Janeiro: Campus, 1992. 
mente com certa margem de discricionaridade) suas decisões. Ele corresponde àquele processo de transformação do poder tradicional, fundado em relações pessoais e patrimoniais, num poder legal e racional, essencialmente impessoal, [... $]^{110}$

O pensamento liberal pretendeu um Estado com poucas leis, mas boas leis, e que respeitassem o indivíduo e garantissem o funcionamento da sociedade maior que representa o conjunto das vontades individuais admitidas pelo Direito Natural dos homens. O Direito passou a ser racionalizado e a separação das atribuições legais em códigos fez deste, trabalho de especialistas e tentacularizado, atingindo com profundidade todos os espaços de vida social. ${ }^{11}$ Neste sentido, surge um direito penal racionalizado que tinha por objetivo dar conta dos delinqüentes e desviantes da norma social. Esta é a novidade no que diz respeito ao Direito. O Direito Moderno adquire autonomia e passa a ser autônomo do monarca, talvez não de sua vontade. $O$ Direito Penal passa a punir em nome da sociedade e em nome do indivíduo. Em nome da sociedade no sentido de impor ao individuo a ordem social, mais ampla e que o submete. Em nome do individuo, no sentido de tornar o sujeito, fora dos padrões de boa conduta moral e social, sociável e dócil, para usar um termo de Foucault. ${ }^{12}$

A partir do desenvolvimento do Direito Moderno, fundado nas bases do liberalismo, toda uma ciência penitenciarista começa a ser montada. Um grande projeto passou a atrair as atenções dos juristas e da sociedade entre os séculos XVIII e XIX. O que antes era desprezado e considerado como o lixo miserável da sociedade passou a ser objeto de ciência. A reforma penitenciária abre o caminho para a construção do objeto da Antropologia Criminal, ou seja, o delinqüente, o crime e o criminoso. Ambos agora podem ser manuseados no gigantesco laboratório sociológico que é o presídio moderno. É este precisamente o sentido da reforma penitenciária. A reforma penitenciária nasce dentro do Estado de Direito. É nele que estão contidos os fundamentos da reforma em niveis político e social. Exercer um poder no indivíduo e não mais sobre o indivíduo. Estas são as bases em que a reforma penitenciária se estabeleceu. Em nome de um Direito Natural, o reformador pretendeu transformar o indivíduo. Esta transformação possui sua base filosófica no liberalismo.

Neste período de efervescência do Direito forma-se paralelamente um novo discurso acerca das causas da criminalidade e do individuo delinqüente. A Criminologia nasce para dar conta da delinqüência e dar uma justificativa científica para a ação normativa do direito de punir. É o momento em que, segundo Foucault, "o poder encontra o nível dos indivíduos, atinge seus corpos, vem se inserir em seus gestos, suas atitudes, seus discursos, sua aprendizagem, sua vida cotidiana". ${ }^{13}$

A modernidade fez com que todos os elementos que compõem a vida social se transformassem de alguma forma em objeto de apreciação analítica, racional e

10 BOBBIO. Op. cit., p. 148.

11 Refiro-me ao movimento de codificação que separou e racionalizou o Direito Moderno. Ver SLVA, Nuno J. Espinosa Gomes "Periodo de influência liberal e individualista (1820-1926)". In Histónia do Direito Português. V1 1, Fontes de Direito. Fundação Calouste Gulbenkian: Lisboa, 1985 p. 291-310.

12 FOUCAULT, Michel. Vigiar e punir: histónia da violência nas prisões. $8^{\mathrm{a}}$ ed. Rio de Janeiro: Vozes, 1991.

13 FOUCAULT, Michel. Microfísica do poder. $9^{2}$ ed. Rio de Janeiro: Graal, 1990. p. 131. 
econômica. Com o presídio moderno não foi diferente. Fez do sujeito social objeto de ciência.

Obviamente o objetivo da reforma penitenciária não possui um único interesse. Seria impossível determinar o sentido exato e o objetivo total da reforma. Podemos, isto sim, dar forma a uma pequena parcela deste caos que se apresenta às nossas vistas. ${ }^{14} \mathrm{O}$ que se apresenta explicitamente é o espírito que esta Reforma representa. Espírito normatizador, racional, disciplinador e que pretende um objetivo. É possível identificar no projeto da reforma penitenciária o espírito da modernidade, sua lógica de ação, no sentido que Weber a conceituou.

É nesse sentido que o conceito de reforma penitenciária pode ser formulado, sem perder de vista o conceito de modernidade e depurado dos paradoxos da lógica da falta. Como foi exposta, grosso modo, a visão de modernidade que pretendo neste trabalho permite uma visão mais ampla da reforma penitenciária no Brasil no século XIX e sua contemporaneidade com as reformas européia e americana, pois estão envolvidas pelo mesmo espírito moderno do mundo ocidental. Trata-se de constituir um saber positivo e aberto. Observar aquilo que foi deixado de lado e foi preferivel não ser visto devido às algemas de uma dogmatização da ciência. Ver um Brasil menos nebuloso, mudar o norte da visão e conseqüentemente ter um novo olhar acerca da modernidade brasileira. A questão, de maneira alguma se fecha, apenas é colocada.

14 Sobre as possibilidades de compreensão da realidade histónico-social ver o texto de Max Weber: "A 'objetividade' do conhecimento nas Ciências Sociais" In COHN, Gabriel. (Org ) Weber 3a ed., Coleção Grandes Cientistas Sociais. São Paulo: Ática, 1986. p. 79. 